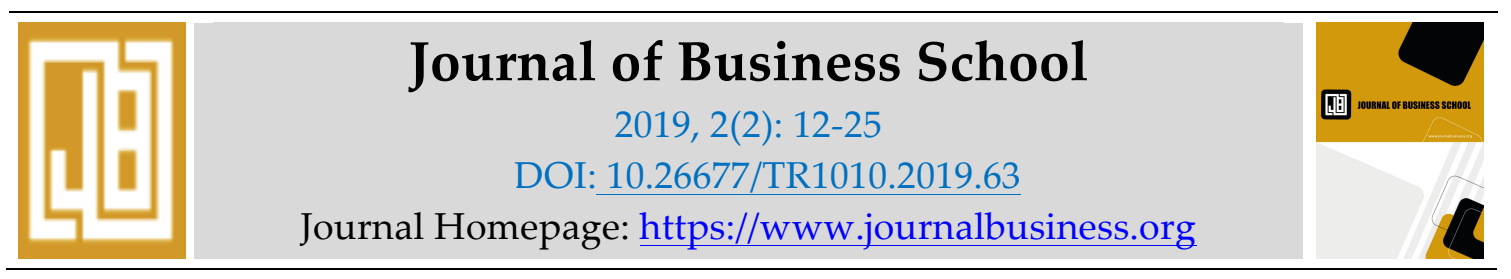

\title{
The Effects of Government Incentives on the Performance of Small and Medium Sized Enterprises in Cameroon: Evidence from Mezam Division
}

\author{
Regina Nchotu Akwanui \\ Pan African Institute of Development, Cameroon. \\ Fabien Sundjo \\ St. Monica University, Cameroon. sundjofabien@rocketmail.com
}

\begin{abstract}
Small and medium sized enterprises (SMEs) are viewed as a catalyst to economic breakthrough and innovation, job creators, and as the nursery bed for large businesses. Despite the important role SMEs play in the economy of a nation and the support the government provides to enhance the performance of this sector, SMEs still find it hard to make the expected contribution to drive forward economic growth and development. This study therefore investigated the effects of government incentives on SMEs performance in the North West Region of Cameroon. Specifically, the study aimed at investigating the effects of: (a) government incentives, (b) the level of education of the managers of SMEs and (c) the age of the enterprise on the performance of SMEs. To achieve these objectives, data was collected using questionnaires with a sample size of 100 owners and managers of SMEs as respondents. These enterprises were chosen through a purposive sampling technique. Data were analysed using both descriptive and inferential statistics. The probit regression model was used to test the specific objectives of the study. The findings from the study showed that incentives positively influence the performance of SMEs. It was also clear from the findings that entrepreneurs with a higher level of education and/or vocational training and experience will decrease the odds for the SME, not to grow by its marginal effect, compared to entrepreneurs with low level of education, no vocational training and no experience. The government should therefore avail information about incentives and involve private sector operators in policy conception. Implementing institution and officers should distribute or allocate incentives fairly and judiciously. SME owners and managers should build their capacity and be dynamic to seek information and seize opportunities that can enhance the performance of their SMEs.
\end{abstract}

Keywords: SME performance, government incentive and probit regression model

\section{Introduction}

SMEs create jobs, generate revenue through taxes and contribute immensely to economic growth (OECD, 2010). SMEs spur up economic breakthrough and innovation and are also the nursery bed for large businesses and the engine of growth of national economies (OECD, 2012). SMEs play a key role in the economic development and poverty reduction in Africa (United 
Nations Economic Commission Policy Brief, 2000). Consequently, African governments have become committed to SME promotion. For example, the government of Angola established Angola's Sovereign Wealth Fund (FSDEA) called Kijinga, which support start-ups and the expansion of new products and services in the outskirts of its cities (FSDEA Annual Report, 2014). Likewise, the Government of Kenya (2007) has also conceived and is running a major strategic plan, known as Vision 2030, in which Information and Communication Technologies (ICTs) and SMEs have been identified as major driving forces for its realization. The government of The Gambia (2011) came up with the Programme for Accelerated Growth and Employment (PAGE) 2012-2015 which principally targets SMEs as the necessary tool for realizing its goals.

SMEs represent $99 \%$ of all firms in developing countries, as well as play a significant role in creating employment opportunities and ensuring social stability (Fjose et al. 2010). The following African countries present the share of SMEs in employment thus: $39 \%$ in Malawi, 38 \% in Kenya, 37 \% in Zambia, 33 \% in Côte d'Ivoire, 32\% in Tanzania, 21\% in South Africa, 20 \% in Burundi, and $19 \%$ in Cameroon. It is worth noting that of all the above mentioned African countries, Cameroon presents the lowest percentage share of SMEs in employment. These facts and declarations show that SMEs are very important in the economic growth of all nations.

The Government of Cameroon has embraced a long-term development vision which aspires to make Cameroon an economic and democratic emerging country by 2035 . The major tool of this vision is the prioritization of SMEs. Law No 2010/001 of 13 April 2010 lays down the general framework for the promotion of SMEs. Similarly, Decree No 2013 / 092 of 3 April 2013 spells out the organization and functioning of the Small and Medium-Sized Promotion Agency as amended and supplemented by decree No 2013/297 of 9 September 2013. This decree provides a package of liberal incentives offering foreign investors opportunities to come in and boost the economy. The government has eased the creation of enterprises through the one-stop shop and facilitated access to finance through the creation of a special bank for SMEs. With these steps, the government of Cameroon shows its understanding that the major driving force towards achieving economic growth and employment is through the creation and growth of the SME sub-sector.

Cameroon is endowed with diverse rich natural resources and is strategically located such that it is considered the regional economic hub and an investment choice for foreign companies given its unlimited access to the sea, large potential market, improvements in regional transport links and the creation and growth of new sectors in the economy (U.S. Department of State, 2014). In addition, Cameroon serves as a transit point for the imports and exports of two landlocked countries in the region namely Chad and The Central African Republic.

Following the above background, Cameroon would have been a very strong economic power in the Central African sub-region but this is not the case because weak governance is hindering its development and ability to attract investments. Cameroon is ranked $153^{\text {rd }}$ out of 180 countries in the 2017 Transparency International corruption perceptions index and $163^{\text {rd }}$ out of 190 economies (Doing Business 2018 Report). Cameroon's poor business environment according to the position the country occupies on the corruption perception index of Transparency International and the World Bank's Doing Business Report 2018 suggests the difficulty SMEs encounter in their performance and growth. SMEs generally still either fail in the first years of activity, or remain very small (OECD, 2016b). They face significant constraints to growth ranging from excessive red tape, ineffectiveness of the different types of support provided and implementation challenges. Gaps exist between policy and implementation. Government policy, regulatory and institutional framework reforms have also not always facilitated and liberated SMEs to perform better and grow but rather, through burdensome regulations and 
taxes, suppress their growth potential (Edmore, 2017). SMEs are often constrained by opaque policies and overbearing regulations (OECD, 2010). Only 36\% of the expected contribution to the country's gross domestic product from SMEs has been attained on a national basis in Cameroon (Ngoa, 2015). This triggers the need for an in-depth investigation into how government incentives and other growth factors affect the performance of SMEs in the context of Mezam Division of the North West Region of Cameroon.

Following the above background and problem statement, the major objective of this research is to investigate the reasons why government's efforts have not attained their objective to encourage the performance of SMEs so that they can realize their full potential and contribute to the economic growth and the country's GDP.

In order to achieve this major objective, the following specific objectives are outlined:

- To investigate the effect of incentives on SME performance

- To appraise the effect of the level of education of the manager of SME on the performance of the SME

- To assess the effect of the age of the SME on its performance

From the background and the main objective of the study, the major research question that arises is: Why has government's efforts not been able to attain the objective of encouraging SMEs performance so that they can realize their full potential and contribute to the economic growth? Following this research question the following specific questions were formulated:

- What is the extent of the effect of incentives on SME performance?

- What is the effect of the level of education of the manager of SME on the performance of the SME?

- What is the effect of the age of SME on its performance?

The gap to be filled by this study, will permit it to act as, a reference point for further research in this domain in Cameroon and other developing countries. Secondly, the positive effect of government incentives on SMEs might not be effective and consistent. Hence, investigating the effects of incentives and other factors that affect SME performance is vital in the context of Cameroon. Policy wise, this study is important because better policy could still be formulated and its implementation controlled and rendered more effective.

The rest of the study is structured as follows: The next Section is aimed at reviewing the literature, while Section three describes the methodology and section four present the findings. Section five focus on the policy implication while section six concludes the paper.

\section{Literature Review}

A lot of research work presenting and analyzing indicators that influence SMEs' performance exist. The findings of such studies are, however, mixed and varied. Doh \& Kim (2014) explored the effects of governmental policies on the innovation of SMEs in the regional strategic industries in South Korea using the technological development assistance funds as understudy. The results indicated that a positive relationship exists between the technological support and performance. Hence, governmental financial aids are important for SME. The objective of another study by Barajas et al. (2016) was based on analyzing the impact of public support on Spanish SMEs performance considering technological and economic variables. The result showed that, there exists a direct and positive impact of government incentives on technological assets of SMEs. In addition, some researches focused on the impact produced by the government support while comparing firms that received the support with those that did not. 
This is the case of studies like those of Maggioni et al. (1999) and Morris \& Stevens (2010). These studies compared firms that received funding or other forms of assistance, with firms that did not. Morris \& Stevens (2010) found that the program had a significant positive impact on sales, although the effect on value-added and productivity was not conclusive. Maggioni et al., (1999) found out that the public program produced mixed effects: government aid allowed firms to have a higher level of technology, but government funding gave rise to entrepreneurial startups, which are not always fully efficient.

Another study aimed at assessing the effectiveness of public support to Small and MediumSized Enterprises (SMEs) in the Brussels-Capital Region in Belgium over the period 2004-2009, focused on research and development subsidies, loans, and equity capital (Fombasso \& Cincera 2015). They measured performance in terms of employment creation in the short-term over a one-year interval. The study employed dummy variables in a comparative or quasiexperimental research design involving a control group selected beforehand through a propensity-score matching procedure. The results obtained revealed that research and development subsidies generally led to better performance, followed respectively by loans and equity capital. This result showed in particular that the type of government incentive to support the enterprise determines the results of their intervention in the SME sector.

Zindiye et al. (2012) investigated the influence of government and other institutions' support on the performance of SMEs in the manufacturing sector in Harare, Zimbabwe. The target population for this study was SME owners or managers. Data analysis was done using the Chisquare to establish the correlation. Ordinal Multinomial Logit Models were used to test for the effects of explanatory variables on those responses that had more than two categories. For the binary responses Ordinary Logit Models were used. To assess or evaluate the association among the response factors, Loglinear Modeling was used. The results indicated that government and other institutions' support are playing a positive role on the performance of SMEs. The statistical programmes ANOVA (Analysis of variance), as well as a regression analysis were employed to statistically test the significance of this assertion. The results indicated that the Zimbabwean government support initiatives play a significant role in determining the performance of SMEs in the manufacturing sector in Harare. The results indicated that there is a positive relationship.

While on one hand effective government assistance may help individual firms overcome institutional and other barriers in an uneven playing field, on the other hand, misguided government support may affect incentives and distort the effective working of market forces. Hansen et al. (2009) analysed whether direct government assistance during start-up and other forms of interaction with the state or public sector have influence on the long-run performance of manufacturing SMEs in Vietnam. They used three partly overlapping surveys during the period 1990-2000 and found that there are strong effects on firm dynamics from interaction with state institutions. Through survey data, they analysed and compared the performance of receivers of initial government assistance with firms receiving no assistance. They used standard parametric regression methods for estimating the average effect of the assistance and tried to find the general average effect by simply estimating the average effect of any kind of direct government support. They further looked more closely at the average effects of specific support programmes to certain sub-groups of the SME's, such as rural versus urban enterprises and household versus non-household enterprises. They found that government support during start-up had no significant impact on enterprise survival, while there was a positive impact on the long-run revenue growth rate. They also looked at the different kinds of government support in more detail and found significant differences between receivers and non-receivers of direct credit assistance among rural enterprises and that non-household enterprises receiving 
temporary tax exemptions have, on average, grown faster compared to their non-receiving counterparts, conditional on other growth determinants. From the results it can therefore be concluded that government assistance helps SMEs improve their performance and survival perspectives.

Trong et al (2017) conducted a study using a panel dataset of private manufacturing SMEs surveys in the period 2007-2015. The study aimed at investigating the effects of government support on firms' financial performance in Vietnam. The dynamic model approach was used. Like the results of previous studies, the findings of this study showed that government assistance affect firms' financial performance. This result is in support of the institutional theory. In addition, the result showed that technical supports from government such as export promotion, human resource training and technology programmes have insignificant influence on the business financial performance. The results also showed that financial support plays an important role, suggesting that supporting measures as tax exemptions, soft loans and investment incentives promote efficiency and are vital for the development of Vietnamese private SMEs.

Other empirical studies have demonstrated how the educational level of the SME owner or manager, his experience, skills and other personal attributes equally influence the performance of SMEs. A study conducted in South Africa by Chiliya \& Roberts-Lombard (2012), investigated the impact of level of experience and education and the age of the business on the financial performance of the small grocery shops in the Mdatsane area in East London Metropole area. Quantitative data was collected and analysis of variance (ANOVA) was carried out. The findings indicated that previous work experiences, education levels and the length of time the business has been in operation have a significant impact on the performance of the business. Another study by Nabintu (2013), sought to establish the factors affecting the performance of small and micro enterprises (SMEs) traders at city park hawkers market in Nairobi County, Kenya. Among other objectives, the study examined how the availability of managerial experience affect the performance of SMEs traders at city park hawkers market in Nairobi County. The study applied survey research design through the use of questionnaires on a sample of 47 SMEs traders. Descriptive statistics was used to summarize the data. Among other findings, the study concluded that government policy and regulations affect the performance of the business to a very great extent. In addition, managerial experience and other attributes also affected the performance of SMEs to a great extent. A study carried out by Isaga (2012) in Tanzania established that there are a number of factors, related to the entrepreneur, the firm and the business environment, which influence the growth of the firm (one measure of firm performance). The research design was quantitative in nature, testing various hypotheses regarding associations between entrepreneurs personal characteristics and firm performance. Specifically, the study hypothesised that certain demographic characteristics, personality traits and cognitive characteristics do have an influence on the performance of SMEs in Tanzania. Data was collected from 300 entrepreneurs (representing SMEs) within the furniture industry in four different regions in Tanzania. Various techniques such as descriptive statistics, Analysis of Variances (ANOVA), factor analysis, regression analysis and Structural Equation Modelling (SEM) were used to analyse the data. The findings revealed that the performance of SMEs is influenced by certain characteristics of the entrepreneurs; entrepreneurs with experience and drive for growth were more likely to have their business perform better than entrepreneurs who lacked the aforementioned attributes. Furthermore, the findings suggest that specific personality traits also exert an influence on the performance of SMEs in Tanzania. We have also found that cognitive characteristics of the entrepreneurs such as entrepreneurial alertness, attitude towards entrepreneurship, different cognitive styles and entrepreneurial motivation 
are positively related to the performance of SMEs. In a study inspired by the high rate of failure of small and medium sized enterprises (SMEs) in Ghana despite many government policies and incentive schemes directed at SMEs, Yeboah (2015), attempts to find out the consequences of the entrepreneur and firm characteristics on SME performance. Data was collected by administering questionnaires to 121 SMEs in the Cape Coast Metropolis. Descriptive statistics and the Cramer's V statistical test were used to analyse the data. The findings showed that the educational qualification of the entrepreneur and size of the enterprise had the most significant influence on SME performance. This study concluded that owner/managers of SMEs must be educated, even if not by formal schooling; they must periodically build their capacity and experience through seminars and workshops to obtain the requisite knowledge and skills to advance their business performance.

On the contrary, Ogubazghi \& Muturi (2014) undertook a study with the objective to find out the influence of owner/manager characteristics on SMEs' access to bank loan. A sample of 87 small and medium manufacturing enterprises was drawn from Asmara city using proportionate systematic sampling. A reliable primary data was collected through semi structured and structured questionnaire. The descriptive and econometric statistical analysis techniques were used to analyze the data. Using the logistic regression, the study found out that the educational level of the owner/manager does not have significant effect on access to bank loan.

Other empirical literature on the effects of the age of the enterprise on the performance of SMEs also presented mixed findings. Olusola et al (2011) studied the effect of age and size of enterprise and the sources of funds available to 480 micro-entrepreneurs randomly selected from the South Western States of Nigeria. The purpose of the research was to highlight the strategic importance of age and size of enterprise as well as the sources of funds available to them to their performances. A comprehensive questionnaire was developed to collect data from the enterprises. Data was analysed using simple descriptive statistics such as pie and bar charts and multiple regression analysis. The equation specified performance as dependent variables and age, size and sources of funds as independent variables. Among other findings in relation to the other factors, it was found that the age of the enterprise has effect on their performance as the relationship was both positive and significant. This revealed that the older the enterprise, the better its performance.

Another study by Rosli (2011) examined factors that determine the performance of SMEs in the Malaysian auto-parts industry. The SMEs were surveyed through a structured questionnaire. Using the multiple regression analysis, it was evident that the age of the enterprise alongside other factors is significantly related to the performance of the SMEs. This consolidates earlier expectations and studies that age and other factors do matter to SMEs performance.

However, a study by Radipere \& Dhliwayo (2014) examined the effect that age and business size have on business performance. A structured research instrument was used to collect data from 500 SMEs in retail industry through interviewer administrated and self-administrated survey. The results showed that there is no significant difference between the age categories; under one year and 20 years and more and business performance. The conclusion is that age does not have any significant influence on the performance of the enterprise.

\section{Methodology}

\section{Model Specification}

Dynamic model approaches are becoming increasingly important in recent years to solve the dynamic nature of economic processes (Flannery \& Hankins, 2013). This dynamic nature makes 
traditional estimation techniques including the Ordinary least squares (OLS) and the fixedeffects (FE) problematic (Flannery \& Hankins, 2013; Wintoki et al., 2012). As shown by many previous studies empirical models using firm performance as a dependent variable must be examined in a dynamic framework in which lagged dependent variable(s) are considered as explanatory variable(s) (Wintoki et al., 2012).

Technically, the inclusion of lagged dependent variable(s) as independent variables of the empirical models allows researchers to control for unobserved historical factors which have potential influences on current enterprise performance, hence reducing omitted variable bias (Wooldridge, 2009).

The relation between dependent and independent variable is specified using a discrete model of probability to quantify the chances that an event will occur. We then think in terms of numbers ranging from 0 to 1 with zero meaning that the event certainly will not occur given by:

$\operatorname{Prob}(\operatorname{Perf}=1)=f(X \beta)$

$\operatorname{Prob}(\operatorname{Perf}=0)=1-\mathrm{f}(\mathrm{X} \beta)$

Where $f$ is the function of repartition through the interval] 0,1 [and $\beta$ is the vector of unknown parameters associated with X. In the logit model,

$\operatorname{Prob}\left(\operatorname{Perf} \mathrm{i}=1 / \mathrm{X}_{\mathrm{i}}\right)=\frac{1}{1+e^{-\alpha-\Sigma_{j}^{n} \beta j X j}}$

$\operatorname{Prob}\left(\operatorname{Perf} \mathrm{f}_{\mathrm{i}}=0 / \mathrm{X}_{\mathrm{i}}\right)=1-\operatorname{prob}\left(\operatorname{Perf}_{\mathrm{i}}=1 / \mathrm{X}_{\mathrm{i}}\right.$

For all $\omega \varepsilon R \mathrm{R}(\omega)=\frac{e^{\omega}}{1+e^{\omega}}=\frac{1}{1+e^{-\omega}}$

The logistic model can be explained in terms of the odds of an event occurring or in terms of marginal effects. The odds of an event occurring are defined as the ration of the probability that an event will occur to the probability that it will not. The logistic regression model used in this study is specified as follows.

$\operatorname{Ln}\left[\frac{\operatorname{Prob}\left(\text { perf } i=\frac{1}{X \bar{i}}\right)}{1-\operatorname{Prob}\left(\operatorname{Perf} i=\frac{1}{X \bar{i}}\right)}\right]=\beta_{0}+\beta_{1}$ Incentives $+\beta_{2}$ Age $+\beta_{3} G e n+\beta_{4} E d u+\beta_{5} \operatorname{Exp}+\beta_{6}$ TrainVoc $+\beta_{7}$ Reg + $\beta_{8}$ Employees $+\beta_{9}$ Scap $+\mu_{i}+\varepsilon$

Where;

Perf=Performance

Incentives=government support,

Gen=gender of respondent,

$E d u=E d u c a t i o n a l$ qualification of respondent,

Exp=Experience,

Age $=$ Years of existence of enterprise

TrainVoc $=$ Vocational training,

Reg=Registered entrepreneurs,

Employees=Number of employees and

Scap=Start-up capital 
Ln stands for natural logarithm, Prob implies probability of performance, $\alpha$ represent the constant term, $\mathrm{n}$ indicates the number of explanatory variables, $X_{i}$ represent the independent variables.

Apriori: $\beta_{0} \neq 0, \beta_{1}>0, \beta_{2}>0, \beta_{3}>0, \beta_{4}>0, \beta_{5}<0, \beta_{6}>0, \beta_{7}>0, \beta_{8}>0, \beta_{9}>0$

Government support or incentive is the main interest variable in the model. $\mu_{\mathrm{i}}$ represents timeinvariant unobserved firm characteristics; denotes time-specific effects which are time-variant and common to all enterprises. These time-specific effects are captured by year dummy variables; $\varepsilon$ is the classical error term. In analyzing the data, we adopted the logit model for the estimation of the parameters because of its mathematical simplicity and ease of interpretation.

Sampling for the study was done by a purposive sampling technique. As such, the selection criteria for this study was the owners and managers of formal SMEs that have been operating for at least three years and have at least two employees. The data for this study were gathered through the use of primary and secondary data sources. The secondary data were obtained from reviewing journals and literature relevant to the subject matter of this research. Official policy documents with relevance to the subject were also consulted. The electronic search site: www.google.com was employed extensively for up-to-date materials on the topic. The primary data formed the crux of this study because it offered the opportunity to obtain at first hand, relevant responses. The primary data source for this study involved the use of a questionnaire.

The sample size of the study was determined taking into consideration its representativeness, the time constraint and the cost that may be involved. A pilot survey of ten questionnaires was conducted in order to ascertain, detect and correct any ambiguities, questions that were not easily understood or poorly constructed and even those that were irrelevant or scary to the respondents. From the responses, remarks and comments that were received on the pilot survey, the entire questionnaire was refined and improved upon to take care of the observed shortcomings, enhance the validity, and make the questions easier and quick to answer. The data is analyzed using STATA 12 SE software. Use is made of the logistic model, due to binary in nature, of our dependent variable and mathematical simplicity and ease of interpretation.

\section{Presentation and Discussion of Findings}

Table 1: Summary of Descriptive Statistics

\begin{tabular}{|c|c|c|c|c|c|}
\hline Variable & obs & Mean & Std. Dev. & $\operatorname{Min}$ & $\operatorname{Max}$ \\
\hline growth & 80 & .775 & .4202169 & 0 & 1 \\
\hline incentives & 80 & .1625 & .3712364 & 0 & 1 \\
\hline$g e n$ & 80 & .5375 & .5017375 & 0 & 1 \\
\hline edu 1 & 80 & 4.35 & 1.351043 & 1 & 6 \\
\hline exp & 80 & .675 & .4713299 & 0 & 1 \\
\hline trainvoc & 80 & .4125 & .4953901 & 0 & 1 \\
\hline reg & 80 & .5375 & .5017375 & 0 & 1 \\
\hline employees & 80 & 1.475 & .7111232 & 1 & 3 \\
\hline scap & 80 & 1.575 & 1.076504 & 1 & 5 \\
\hline
\end{tabular}

Source: Generated by Authors Using STATA 12 SE 
The results presented on the table above shows the summary of the descriptive statistics for the variables included in the model of the study. We observe from the table that all the variables included in the models of the study have low standard deviations compared to the mean of the variables. None of the variables have a standard deviation higher than its mean value. All variables in the models are showing low deviations from their mean values. The distribution of the variables included in the model are too spread from the center of their distributions, the variability of the distribution is therefore low and therefore not far away from the center of the distribution. The variables included in the models of the study are therefore showing good distribution as their measures of variability values are lower than their average values.

Table 2: Pair-wise Correlation Matrix

\begin{tabular}{|c|c|c|c|c|c|c|c|}
\hline & growth & incent $\sim s$ & gen & edu & exp & trainVoc & reg \\
\hline growth & 1.0000 & & & & & & \\
\hline incentives & -0.0052 & 1.0000 & & & & & \\
\hline gen & -0.0964 & -0.0671 & 1.0000 & & & & \\
\hline$e d u$ & 0.1175 & -0.1319 & 0.1166 & 1.0000 & & & \\
\hline exp & 0.0545 & 0.0886 & 0.1592 & 0.0051 & 1.0000 & & \\
\hline trainVoc & -0.0370 & 0.2504 & 0.1152 & -0.1470 & 0.0935 & 1.0000 & \\
\hline$r e g$ & 0.1215 & 0.2727 & 0.0446 & -0.0738 & 0.2663 & 0.3699 & 1.0000 \\
\hline employees & -0.0623 & 0.0875 & 0.1268 & 0.1914 & 0.1643 & 0.1554 & 0.0559 \\
\hline \multirow[t]{2}{*}{ scap } & 0.0828 & 0.2067 & -0.0639 & 0.0643 & -0.2258 & 0.0243 & 0.4986 \\
\hline & employ s & scap & & & & & \\
\hline employees & 1.0000 & & & & & & \\
\hline scap & -0.1298 & 1.0000 & & & & & \\
\hline
\end{tabular}

Source: Generated by Author Using STATA 12 SE

The result on the table above represents the pair-wise correlation matrix which shows the correlation which exists among the variables included in the models of the study. The correlation coefficients of the leading diagonals stand at 1.0000 which indicates that each explanatory variable is perfectly collinear to itself. Furthermore, the results show a weak negative correlation between some of the variables in the study while there exist a weak positive correlation between other explanatory variables of the models. We observe weak positive and negative correlations amongst all other explanatory variables indicating the possible absence of the problem of multicollinearity in the models of the study. 
Table 3: Logistic Regression Results

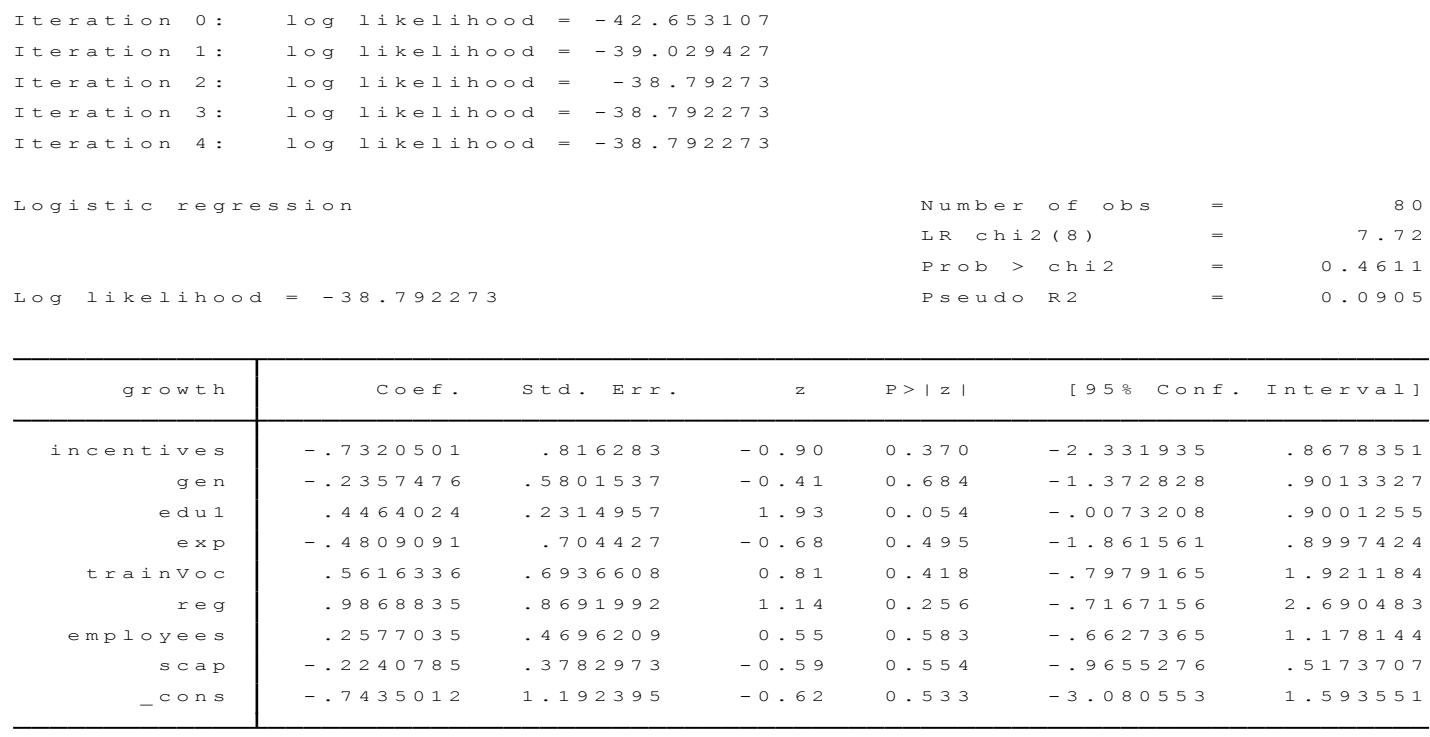

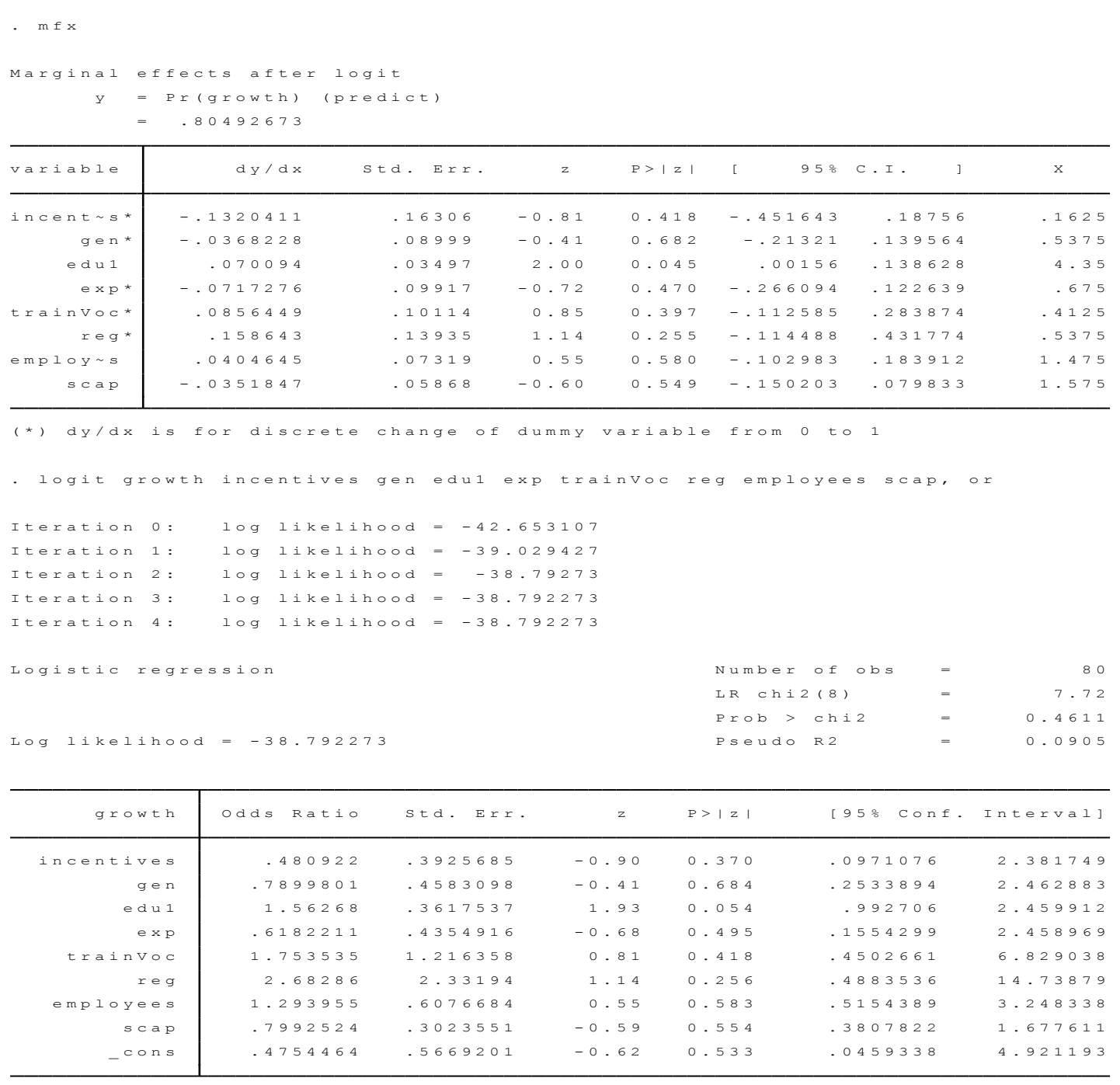

Source: Generated by Authors Using STATA 12 SE

Note: No, for no growth is the based outcome. Yes, for growth is the alternative outcome. 
The findings on the table above show that an enterprise that receives incentives will decrease the likelihood for the SMEs not to grow by its marginal effect of .1320411 compared to another enterprise that does not receive incentives. The findings also show that an increase in the incentives will decrease the odds for the SMEs not to grow by its odd ratio of .480922 compared to another enterprise that does not receive incentives.

The findings further show that a one year increase in the level of education will increase the likelihood for the SMEs not to grow by its marginal effect of .070094 . The findings also show that a one year increase in the level of education will increase the odds for the SMEs not to grow by its odd ratio of 1.56268 . The findings therefore show how education instead decreases growth and performance of SMEs.

The findings again showed that entrepreneurs with experience will decrease the likelihood for the SMEs not to grow by its marginal effect of .0717276 compared to entrepreneurs with no experience. The findings also show that entrepreneurs with experience will decrease the odds for the SMEs not to grow by its odd ratio of .6182211 entrepreneurs with no experience.

The findings showed that entrepreneurs with vocational training will increase the likelihood for the SMEs not to grow by its marginal effect of .0856449 compared to entrepreneurs with no vocational training. The findings also show that entrepreneurs with vocational training will increase the odds for the SMEs not to grow by its odd ratio of 1.753535 entrepreneurs with no vocational training.

\section{Policy Implications of the Findings}

There are contributions on the impact of government support to the SMEs' performance in developing countries, and these reach different conclusions. On the one hand, effective government assistance may help individual firms overcome institutional and other barriers in an uneven playing field. On the other hand, misguided government support may affect incentives and distort the effective working of market forces. This study found out that incentives increase the growth of SMEs in Cameroon. This finding is in line with the results of Zindiye et al., (2012) who investigated the influence of government and other institutions' support on the performance of SMEs in the manufacturing sector. They observed that there is a positive relationship. Similar results to those obtained in this study is that of Hansen et al. (2009) who analysed whether direct government assistance during start-up and other forms of interaction with the state or public sector have influence on the long-run performance of manufacturing SMEs in Vietnam. From the results they obtained it could be concluded that government assistance helps SMEs improve their performance and survival perspectives. The implication of the findings is that government support programs have the capability to improve the performance of SMEs in Cameroon.

The findings in this study are also in agreement with those of Nabintu (2013) whose study on the factors affecting the performance of small and micro enterprises (SMEs) traders at city park hawkers market in Nairobi County, Kenya showed that that government policy and regulations affect the performance of the business to a very great extent.

Findings from the study also showed that the level of education of the manager or SME owner does not significantly affect the performance of the SME. This outcome ties with the findings of Ogubazghi \& Muturi (2014) who also found out that the educational level of the owner/manager does not have significant effect on access to bank loan. 
Further findings also showed that the age of the enterprise affect its performance. This agrees with the findings of Olusola et al (2011). This revealed that the older the enterprise, the better its performance.

However, like in the findings in this study, Nabintu (2013); Chiliya \& Roberts-Lombard (2012) further found out that managerial experience and other attributes also affected the performance of SMEs to a great extent. The findings indicated that previous work experiences, education levels and the length of time the business has been in operation have a significant impact on the performance of the enterprise.

\section{Conclusion}

In general, the notion of government incentives to SMEs in Bamenda needs to be addressed as the attitude of business operators towards government incentives is that of distrust and doubt. Government incentives are important and can improve the performance and growth of SMEs. However, most SMEs have not benefitted because their knowledge on available government incentives and eligibility requirements is very low. Others are discouraged by the administrative bottlenecks and the perception of biased and unfair conditions surrounding the application and incentive allocation procedures.

Implementing institutions should ensure that entrepreneurs are always motivated and encouraged to make use of the incentives and opportunities to perform better and grow their enterprises. This is by changing the SMEs perception through involvement because already they feel that incentives distribution and allocation are not fair and that some politicians or influential people capture or hijack the initiatives for political ends. They should also make incentives policies and other regulatory laws and requirements easy to understand, while at the same time penalizing those implementing officers who are corrupt or biased.

\section{References}

Barajas, A., Huergo, E. and Moreno, L. (2016). SME Performance and Public Support for International RJVs. Journal of Small Business Management 54(4):1206-1228 - Available at https://www.researchgate.net/publication/308632355_SME_Performance_and_Public_Su pport_for_International_RJVs DOI: 10.1111/jsbm.12221 Accessed on 03/06/2018

Chiliya, N. and Roberts-Lombard, M. (2012). Impact of Level of Education and Experience on Profitability of Small Grocery Shops in South Africa. International Journal of Bussiness Management and Economic Research., Vol 3(1).

Doh, S. \& Kim, B. (2014). Government support for SME innovations in the regional industries: The case of government financial support program in South Korea. Research Policy, 43(9), 1557-1569.

Doing Business (2018). A World Bank Group Flagship Report. Comparing Business Regulation for Domestic Firms in 190 Economies. Doing Business 2018. Reforming to Create Jobs. www.doingbusiness.org/content/dam/doingBusiness/...Reports/.../DB2018-FullReport.p...

Edmore, M. (2017). The Impact of Legal and Regulatory Framework on SMEs Development: Evidence from Zimbabwe Research Journal of Finance and Accounting www.iiste.org Vol.8, No.20. Accessed on 22/10/18. 
Fjose, S., Grünfeld, L.A. and Green, C. (2010) SMEs and Growth in Sub-Saharan AfricaIdentifying SME Roles and Obstacles to SME Growth. MENON Business Economics, MENON Publication No. 14/2010, Oslo, Norway.

Flannery, M. J. and Hankins, K. W. (2013). Estimating dynamic panel models in corporate finance. Journal of Corporate Finance. Volume 19, Pages 1-19. Available at: htt://dx.doi.org. Accessed on 09/09/2018.

Fombasso, G. E. and Cincera, M. (2015). Optimal Effectiveness of Government intervention in the SME sector: Evidence from the Brussels-Capital Region.

Ngoa, L.S.E. (2015). Minister of Small and Medium Sized Enterprises, Social Economy and Handicraft in an interview on Wednesday, 05 August 2015). Available at http://www.businessincameroon.com/ Accessed on 12/6/2018.

Hansen, H.; Rand, J. and Tarp, F. (2009). Enterprise Growth and Survival in Vietnam: Does Government Support Matter? The Journal of Development Studies, Vol. 45, No. 7, 10481069 Available at: http://www.tandfonline.com/loi/fjds20 Accessed on 27/11/2018.

Isaga, N. (2012). Entrepreneurship and the growth of SMEs in the Furniture Industry in Tanzania.

Maggioni, V., Sorrentino, M. and Williams, M. (1999). Mixed Consequences of Government Aid for New Venture Creation: Evidence from Italy. Journal of Management and Governance 3(3):287-305. Available at https://www.researchgate.net/publication/226283661DOI: 10.1023/A:1009922725925 Accessed on 10/10/2018

Morris, M., and Stevens, P. (2010). Evaluation of a New Zealand business support programme

Using firm performance micro-data. Small Enterprise Research, 17(1), 30-42

Nabintu N. (2013). Factors Affecting the Performance of Small and Micro Enterprises (SMEs) Traders at City Park Hawkers Market in Nairobi County, Kenya.

OECD, (2010). "High-growth enterprises: What governments can do to make a difference, OECD studies on SMEs and entrepreneurship," Organisation for Economic Cooperation and Development (OECD), Paris.

OECD, (2012). Economic Outlook, Volume 2012 Issue 1Avalable at https://www.oecdilibrary.org/economics/oecd-economic-outlook-volume-2012-issue-1

OECD, (2016b). Entrepreneurship at a Glance 2016, OECD Publishing, Paris. Available at https://www.oecd.org/mcm/documents/C-MIN-2017-8-EN.pdf Accessed on 23/10/2018.

Ogubazghi, S.K. and Muturi, W. (2014). The Effect of Age and Educational Level of Owner/Managers on SMMEs' Access to Bank Loan in Eritrea: Evidence from Asmara City. American Journal of Industrial and Business Management, 4, 632-643. http://dx.doi.org/10.4236/ajibm.2014.411069

Olusola, A. O., Oladejo, A, J. O., Morufu, O. and Abimbola, A. O. (2011). Performance Analysis of the Strategic Effect of Age, Size and Sources of Funds on Micro Enterprises in Nigeria. Journal of Emerging Trends in Economics and Management Sciences (JETEMS) 2 (6): 483489 @ Scholarlink Research Institute Journals, 2011 jetems.scholarlinkresearch.org.

Radipere, S. and Dhliwayo, S. (2014). The role of age and business size on small business performance in the South African small enterprise sector. Problems and Perspectives in Management, 12 (4) JOURNAL "Problems and Perspectives in Management" FOUNDER LLC “Consulting Publishing Company “Business Perspectives. 
Rosli M. M. (2011). Determinants of small and medium enterprises performance in the Malaysian auto-parts industry. African Journal of Business Management Vol. 5(20), pp. 8235-8241, Available online at http://www.academicjournals.org/AJBM DOI: 10.5897/AJBM11.889 ISSN 1993-8233 @2011 Academic Journals.

The Government of the Republic of Kenya (2007). Kenya Vision 2030 Available at: www.fao.org/fileadmin/user_upload/drought/docs/vision\%202030\%20popular\%20Versio n.pdf. Accessed on 22/9/2018.

The Republic of The Gambia (2011) Programme for Accelerated Growth and Employment (PAGE) 2012-2015 Ministry of Finance and Economic Affairs, available at;www.tangogambia.org/wp-content/uploads/downloads/2011/11/Gambia_PAGE-20122015.pdf. Accessed on 22/9/2018.

Trong, N.; Van, H. V. and Bartolacci F. (2017). Government support and firm financial performance: New evidence from a transitional economy. Available at https://mpra.ub.uni-muenchen.de/81752/MPRA Paper No. 81752, posted 3 October 2017 14:55 UTC.

U.S. Department of State: 2014 Investment Climate Statement June 2014.

Wintoki, M. B., Linck, J. S., \& Netter, J. M. (2012). Endogeneity and the dynamics of internal corporate governance. Journal of Financial Economics, 105(3), 581-606.

Wooldridge, J. M. (2009). Introductory econometrics: A modern approach (4 ed.). Mason, USA: South-Western Cengage Learning.

Yeboah, M. A. (2015). Determinants of SME growth: An Empirical Perspective of SMEs in the cape coast metropolis, Ghana. The Journal of Business in Developing Nations Volume 14

Zindiye, S.; Chiliya, N. and Masocha, R. (2012). The impact of Government and other Institutions' support on the Performance of Small and Medium Enterprises in the Manufacturing Sector in Harare, Zimbabwe. Available at: https://www.researchgate.net/publication/235906937__ [Accessed Jan 02 2019]. 